\title{
Sickle cell anemia - Nitric oxide related genetic modifiers of hematological and biochemical parameters
}

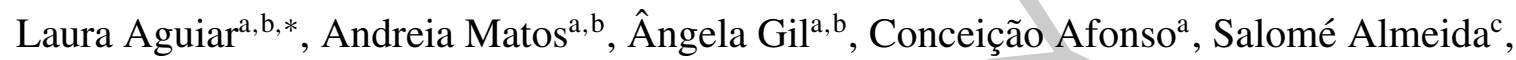
Lígia Braga $^{\text {d }}$, João Lavinha ${ }^{\mathrm{e}}$, Paula Kjollerstrom ${ }^{\mathrm{d}}$, Paula Faustino ${ }^{\mathrm{e}}$, Manuel Bicho ${ }^{\mathrm{a}, \mathrm{b}}$ and Ângela Inácio ${ }^{\mathrm{a}, \mathrm{b}}$

${ }^{a}$ Laboratório de Genética, Instituto de Saúde Ambiental, Faculdade de Medicina da Universidade de Lisboa, Lisbon, Portugal

${ }^{\mathrm{b}}$ Instituto de Investigação Científica Bento da Rocha Cabral, Lisbon, Portugal

' Serviço de Genética Médica, Hospital de Dona Estefânia, Lisbon, Portugal

${ }^{\mathrm{d}}$ Unidade de Hematologia, Hospital de Dona Estefânia, Lisbon, Portugal

e Departamento de Genética Humana, Instituto Nacional de Saúde Doutor Ricardo Jorge, Lisbon, Portugal

\begin{abstract}
.
BACKGROUND: Sickle cell anemia (SCA) is an inherited blood disorder. SCA patients present clinical and hematologic variability that cannot be only explained by the single mutation in the beta-globin gene. Others genetic modifiers and environmental effects are important for the clinical phenotype. SCA patients present arginine deficiency that contributes to a lower nitric oxide (NO) bioactivity.

OBJECTIVE: The aim of this work is to determine the association between hematological and biochemical parameters and genetic variants from eNOS gene, in pediatric SCA patients.

METHODS: 26 pediatric SCA patients were genotyped using polymerase chain reaction (PCR) and restriction fragment length polymorphism (RFLP) techniques in three important $e N O S$ gene polymorphisms - rs2070744, rs 1799983 and intron 4 VNTR.

RESULTS: Results from this study show a significant statistical association between some parameters and genetic variants: an increased reticulocyte count and high serum lactate dehydrogenase levels were associated with both the rs2070744_TT and the rs1799983_GG genotypes at $e N O S$ gene and high levels of neutrophils were associated with the $e N O S 4 a$ allele at intron 4 VNTR.

CONCLUSIONS: Our results reinforce the importance of NO bioactivity in SCA. We presume that NO, and its precursors might be used as therapy to improve the quality of life of SCA patients.
\end{abstract}

Keywords: Sickle cell anemia, genetic modifiers, nitric oxide

\section{Introduction}

Sickle cell anemia (SCA) is an autosomal recessive hereditary anemia characterized by the presence of hemoglobin $\mathrm{S}(\mathrm{Hb} \mathrm{S})$ and is one of the most common human genetic disorders world-wide [20], This disease is caused by a single point mutation in the beta-globin gene, located on chromosome 11, with a corresponding amino acid substitution at the sixth position of the beta-globin chain [10]. Hemolytic

\footnotetext{
*Corresponding author: Laura Aguiar, Instituto de Investigação Científica Bento da Rocha Cabral, Lisbon, Portugal. Tel.: +351 9668350 73; E-mail: laurasoaresaguiar@gmail.com.
} 
anemia and vaso-occlusion are the major features of this disease. Red blood cell rheology and adhesiveness play a key role in the occurrence of vaso-occlusive like events in sickle cell anemia, with stiffness of sickle erythrocytes and topography of cell membrane affecting adhesion to the endothelium [2].

SCA patients present clinical and hematologic variability that cannot be only explained by the single mutation in the beta-globin gene. Others genetic modifiers and environmental effects are important in the clinical phenotype [18]. Nitric oxide (NO), a gas with potent vasodilation, antiadhesive and antioxidative properties, represents a critical molecule for proper endothelial function and maintenance of a patent vascular lumen [7, 17]. A study shows that systemic vascular resistance in SCA is positively correlated with red blood cell deformability, and negatively with nitric oxide metabolites level in SCA children [12]. The endothelial NO synthase (eNOS), an enzyme that generates NO, is expressed in the endothelium, encoded by a gene (eNOS) located on chromosome 7 [19]. A recent study found that red blood cell nitric oxide synthase modulates red blood cell deformability in SCA [14]. SCA patients present endothelial dysfunction due to impaired bioavailability of endogenous nitric oxide caused by scavenging of NO by cell-free plasma hemoglobin and consumption of L-arginine amino acid by cell-free arginase enzyme released from hemolyzed red blood cell [24]. Several polymorphic variants have been described in the eNOS gene [6]. The present study aims to explore the association between hematological and biochemical parameters with genetic variants from eNOS gene, in pediatric SCA patients.

\section{Patients and methods}

\subsection{Patients}

We investigated 26 patients with SCA (18 males and 8 females) followed up in Hospital de Dona Estefânia, in Lisbon. Their age ranged from 3 to 19 years with a mean of $8.58 \pm 5.25$ years. An informed consent was obtained from the guardian of each patient before participation. This study was approved by the University of Lisbon's Committee on Ethics.

\subsection{Phenotypic characterization}

$\mathrm{Hb} \mathrm{S}$, total $\mathrm{Hb}$, red cell distribution width (RDW), levels of leukocytes, levels of neutrophils, serum lactate dehydrogenase (LDH), total bilirubin and reticulocyte count were collected from the patients' hospital records and these parameters were obtained during the steady-state periods. Acid phosphatase (ACP1) enzymatic activity was determined in erythrocytes as described by Dissing, Dahl e Svansmark [9]. Transmembrane reductase (TMR) was performed using an adapted method modified by Orringer and Roer [15]. Methemoglobin reductase (MetHbR) was determined using an adapted method modified by Board \& Pidcock [3]. Myeloperoxidase (MPO) was determined by ELISA (R\&D Systems Inc.).

\subsection{Genotyping}

Amplification of DNA samples for polymorphic analysis of variable number of tandem repeats (VNTR) in intron 4 (27 bp tandem repeat) was performed by polymerase chain reaction (PCR). Amplification of DNA samples for polymorphic analysis of single nucleotide polymorphism (SNP) rs2070744 and SNP rs 1799983 were performed by PCR followed by restriction fragment length analysis. Adherence to the Hardy-Weinberg equilibrium constant was confirmed. The homozygous status for the SCA mutation (HBB:c.20A $>$ T) was confirmed by PCR followed by Bsu36I restriction fragment length analysis by agarose gel electrophoresis. 


\subsection{Statistical analysis}

Association studies were performed using $T$ test/ ANOVA parametric tests $(\mathrm{Hb} \mathrm{S}$, total $\mathrm{Hb}$, RDW, levels of neutrophils, ACP1, TMR, MetHbR, MPO and reticulocyte count) or Mann-Whitney/ Kuskal-Wallis non-parametric tests (levels of leukocytes, LDH and total bilirubin). eNOS gene haplotypes were estimated. All tests were performed with SPSS 22.0 software. Statistical significance was defined as a $P$-value $<0.05$.

\section{Results}

Polymorphisms analyzed for the $e N O S$ gene are: the variable number of tandem repeats in intron 4, eNOS 4a/b; a SNP in the promoter region, rs2070744; and another in exon 7, rs1799983. Results from this study show a significant statistical association between some parameters and genetic variants at $e N O S$ gene. An increased reticulocyte count and high LDH levels were associated with both the rs2070744_TT (Table 1 and Fig. 1) and the rs1799983_GG genotypes (Table 2 and Fig. 2) and high levels of neutrophils were associated with the eNOS4a allele at intron 4 VNTR (Table 3 and Fig. 3). Rs2070744_CC was not found in the population. There is no significant difference between the other parameters and genetic variants/ haplotypes at eNOS gene (Tables 1, 2, 3 and 4).

\section{Discussion}

Sickle cell anemia is one of the most common human genetic disorders world-wide and represents a major public health problem. Considering the unusual clinical heterogeneity, it is imperative that the significance of polymorphisms with clinical relevance be delineated.

In this study we analyzed three well-characterized polymorphisms: intron 4 (27 bp VNTR), rs2070744 (-786TC) and rs1799983 (Glu298Asp). Results showed a significant statistical association between commonly measured hemolysis biomarkers and two of the $e N O S$ polymorphisms, an increased reticulocyte count and high LDH levels were associated with both, the rs2070744_TT (Table 1 and Fig. 1) and the rs1799983_GG (Table 2 and Fig. 2) genotypes at eNOS gene. Concerning rs2070744_TT,

Table 1

Association between hematological and biochemical parameters and rs2070744 genotypes (TT and CT) at $e N O S$ gene

\begin{tabular}{|c|c|c|c|}
\hline Parameters & TT & $\mathrm{CT}$ & $p$-value \\
\hline Total Hb (g/dL) & $8.23 \pm 1.20(13)$ & $9.14 \pm 1.28(10)$ & $0.095^{1}$ \\
\hline $\mathrm{Hb} \mathrm{S}(\%)$ & $76.26 \pm 6.08(12)$ & $73.06 \pm 7.11(10)$ & $0.268^{1}$ \\
\hline Total bilirubin (mg/dL) & $1.74 ; 1.26-2.80(7)$ & $2.00 ; 1.30-5.57(5)$ & $0.530^{2}$ \\
\hline LDH (U/L) & $490.00 ; 410.00-793.00(7)$ & $371.50 ; 328.00-451.00(4)$ & $0.042^{2}$ \\
\hline RDW (\%) & $22.53 \pm 1.93(7)$ & $20.73 \pm 3.12(3)$ & $0.288^{1}$ \\
\hline Reticulocyte count (\%) & $9.56 \pm 3.43(13)$ & $6.12 \pm 2.50(10)$ & $0.015^{1}$ \\
\hline 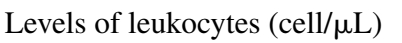 & $12300.00 ; 7000.00-33100.00(7)$ & $10400.00 ; 10200.00-10500.00$ (3) & $0.667^{2}$ \\
\hline Levels of neutrophils (cell/ $\mu \mathrm{L}$ ) & $5287.86 \pm 2339.76(7)$ & $4666.67 \pm 1776.30(3)$ & $0.695^{1}$ \\
\hline $\mathrm{ACP} 1(\mu \mathrm{mol} / \mathrm{g} \mathrm{Hb} / \mathrm{h})$ & $357.26 \pm 57.00(7)$ & $379.95 \pm 146.08(7)$ & $0.712^{1}$ \\
\hline MPO (ng/mL) & $38.98 \pm 20.17(8)$ & $35.40 \pm 17.86(6)$ & $0.737^{1}$ \\
\hline MetHbR ( $\mu \mathrm{mol} / \mathrm{g} \mathrm{Hb} / \mathrm{min})$ & $27.39 \pm 12.13(6)$ & $21.02 \pm 5.80(7)$ & $0.240^{1}$ \\
\hline TMR (mmol/lcell/h) & $4.90 \pm 0.27(2)$ & $5.43 \pm 1.73(2)$ & $0.711^{1}$ \\
\hline
\end{tabular}

\footnotetext{
${ }^{1} T$ test - Mean \pm standard deviation ( - sample size). ${ }^{2}$ Mann-Whitney test - Median; minimum - maximum ( - sample size).
} 
a)

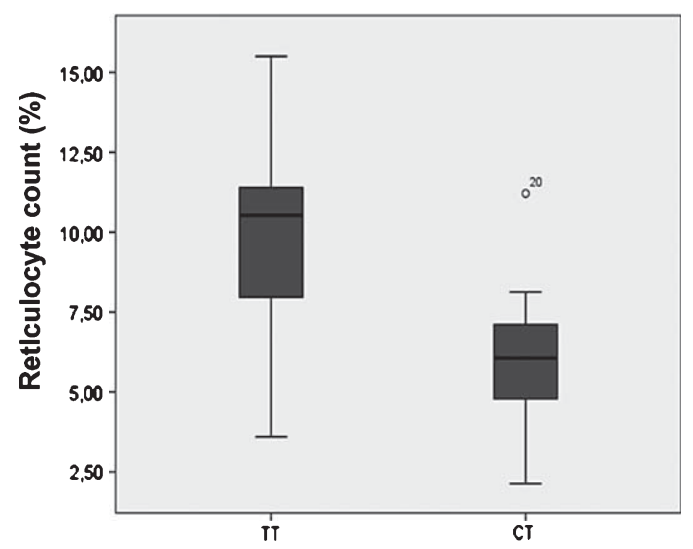

b)

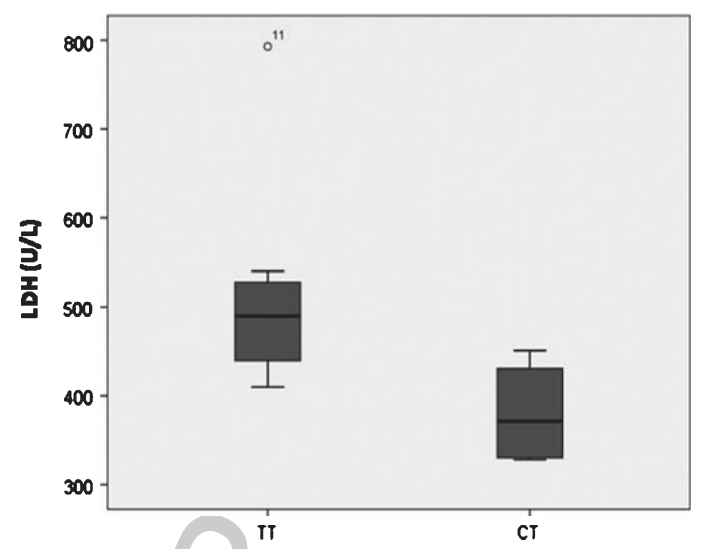

Fig. 1. Box plots of the distribution of reticulocyte count (a) and LDH level (b) in rs2070744 genotypes (TT and CT) at $e N O S$ gene.

Table 2

Association between hematological and biochemical parameters and rs 1799983 genotypes (GG and GT/TT) at $e N O S$ gene

\begin{tabular}{lccc}
\hline Parameters & GG & GT ou TT & $p$-value \\
\hline Total Hb (g/dL) & $8.46 \pm 1.18(17)$ & $9.02 \pm 1.77(5)$ & $0.412^{1}$ \\
Hb S $(\%)$ & $75.04 \pm 6.40(16)$ & $76.46 \pm 5.99(5)$ & $0.665^{1}$ \\
Total bilirubin $(\mathrm{mg} / \mathrm{dL})$ & $1.70 ; 1.26-2.80(8)$ & $3.73 ; 1.40-5.57(4)$ & $0.154^{2}$ \\
LDH $(\mathrm{U} / \mathrm{L})$ & $490.00 ; 410.00-793.00(7)$ & $371.50 ; 328.00-451.00(4)$ & $0.042^{2}$ \\
RDW $(\%)$ & $21.86 \pm 2.59(8)$ & $22.50 \pm 0.85(2)$ & $0.750^{1}$ \\
Reticulocyte count $(\%)$ & $9.20 \pm 3.21(17)$ & $4.53 \pm 1.75(5)$ & $0.006^{1}$ \\
Levels of leukocytes $(\mathrm{cell} / \mu \mathrm{L})$ & $11250.00 ; 7000.00-33100.00(8)$ & $10450.00 ; 10400.00-10500.00(2)$ & $1.000^{2}$ \\
Levels of neutrophils (cell/ $\mu \mathrm{L})$ & $5010.63 \pm 2303.76(8)$ & $5465.00 \pm 1576.85(2)$ & $0.803^{1}$ \\
ACP1 $(\mu \mathrm{mol} / \mathrm{g} \mathrm{Hb} / \mathrm{h})$ & $339.82 \pm 72.23(8)$ & $438.45 \pm 130.03(5)$ & $0.103^{1}$ \\
MPO $(\mathrm{ng} / \mathrm{mL})$ & $40.09 \pm 19.16(9)$ & $32.69 \pm 18.53(5)$ & $0.498^{1}$ \\
MetHbR $(\mu \mathrm{mol} / \mathrm{g} \mathrm{Hb} / \mathrm{min})$ & $26.04 \pm 11.64(7)$ & $23.36 \pm 4.75(5)$ & $0.640^{1}$ \\
TMR $(\mathrm{mmol} / \mathrm{lcell} / \mathrm{h})$ & $4.90 \pm 0.27(2)$ & $5.43 \pm 1.78(2)$ & $0.711^{1}$ \\
\hline
\end{tabular}

${ }^{1} T$ test - Mean \pm standard deviation ( $\mathrm{n}$ - sample size). ${ }^{2}$ Mann-Whitney test - Median; minimum - maximum ( $\mathrm{n}$ - sample size).

results are not unexpected since the corresponding $\mathrm{T}$ allele in the promoter region was already reported associated with lower levels of gene expression [22]. Our results confirm once more a functional effect of this polymorphism on $e N O S$ gene. Regarding the other polymorphism (rs1799983), its effect is still controversial since the aspartate substitution at 298 does not seem to have a major effect in modulating eNOS activity in vivo [21], however an association of the T allele with pre-eclampsia [11] and ischemic heart disease [5] was reported strengthening the importance of this polymorphism. Studies with intron 4 VNTR polymorphism revealed an association between the $4 \mathrm{a}$ allele with coronary heart disease [16] and renal disease [4, 23]. Another study found that eNOS intron 4 VNTR gene polymorphism is related to endothelial dysfunction and vasculopathy in sickle cell disease [19]. As modulators of the inflammatory response, neutrophils are in high number in SCA patients. In this study higher number of neutrophils were associated with the eNOS4a allele (Table 3 and Fig. 3). NO exerts regulatory effects on neutrophil, with low concentrations being stimulatory [1,8]. A study showed that levels of expression of two of the alleles $(e N O S 4 a / b)$ dependents on the promoter SNP rs2070744 [22]. Thus, 
a)

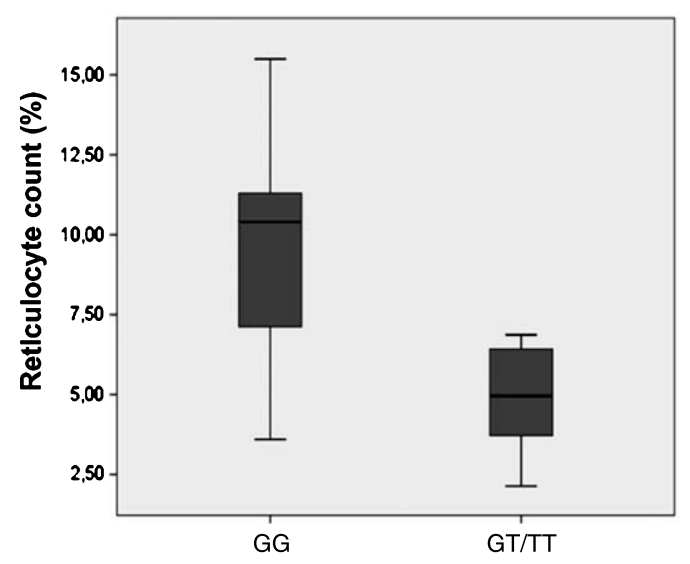

b)

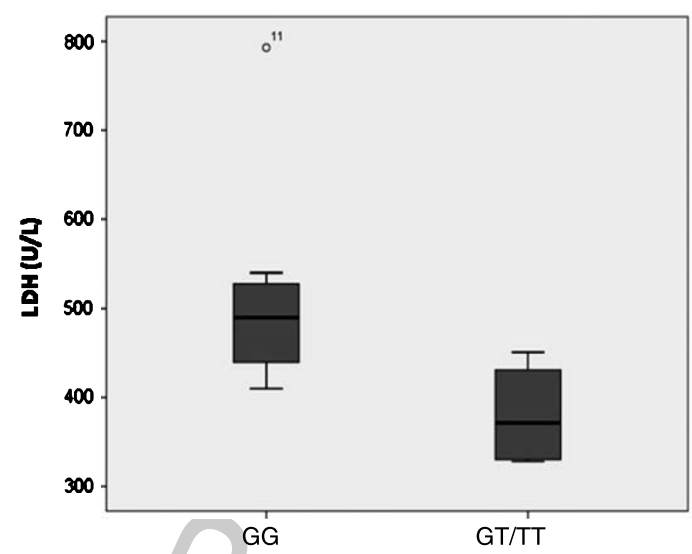

Fig. 2. Box plots of the distribution of reticulocyte count (a) and LDH level (b) in rs 1799983 genotypes (GG and GT/TT) at eNOS gene.

Table 3

Association between hematological and biochemical parameters and the presence or absence of eNOS4a allele at $e N O S$ gene

\begin{tabular}{|c|c|c|c|}
\hline Parameters & Presence of $4 \mathrm{a}$ allele & Absence of $4 \mathrm{a}$ allele & $p$-value \\
\hline Total $\mathrm{Hb}(\mathrm{g} / \mathrm{dL})$ & $8.26 \pm 1.01(13)$ & $9.10 \pm 1.51(10)$ & $0.125^{1}$ \\
\hline $\mathrm{Hb} \mathrm{S}(\%)$ & $76.16 \pm 6.58(12)$ & $73.18 \pm 6.59(10)$ & $0.304^{1}$ \\
\hline Total bilirubin (mg/dL) & $1.74 ; 1.30-2.80(7)$ & $2.00 ; 1.26-5.57(5)$ & $0.530^{2}$ \\
\hline LDH (U/L) & $477.50 ; 411.00-793.00(6)$ & $410.00 ; 328.00-516.00(5)$ & $0.126^{2}$ \\
\hline RDW (\%) & $22.28 \pm 2.69(7)$ & $21.30 \pm 1.21(3)$ & $0.570^{1}$ \\
\hline Reticulocyte count (\%) & $8.68 \pm 3.50(13)$ & $7.27 \pm 3.43(10)$ & $0.346^{1}$ \\
\hline Levels of leukocytes (cell/ $\mu \mathrm{L})$ & 12300.00; 9800.00-33100.00 (7) & $10200.00 ; 7000.00-10400.00$ (3) & $0.117^{2}$ \\
\hline Levels of neutrophils (cell/ $\mu \mathrm{L}$ ) & $5942.14 \pm 1800.85(7)$ & $3140.00 \pm 1417.78(3)$ & $0.045^{1}$ \\
\hline ACP1 ( $\mu \mathrm{mol} / \mathrm{g} \mathrm{Hb} / \mathrm{h})$ & $377.90 \pm 122.59(8)$ & $356.20 \pm 92.20(6)$ & $0.723^{1}$ \\
\hline MPO (ng/mL) & $40.43 \pm 20.06(9)$ & $32.07 \pm 16.14(5)$ & $0.442^{1}$ \\
\hline MetHbR ( $\mu \mathrm{mol} / \mathrm{g} \mathrm{Hb} / \mathrm{min})$ & $25.88 \pm 11.08(8)$ & $20.88 \pm 5.73(5)$ & $0.375^{1}$ \\
\hline TMR (mmol/lcell/h) & $4.64 \pm 0.62(2)$ & $5.68 \pm 1.37(2)$ & $0.436^{1}$ \\
\hline
\end{tabular}

${ }^{1} T$ test - Mean \pm standard deviation (n - sample size). ${ }^{2}$ Mann-Whitney test - Median; minimum - maximum (n - sample size).

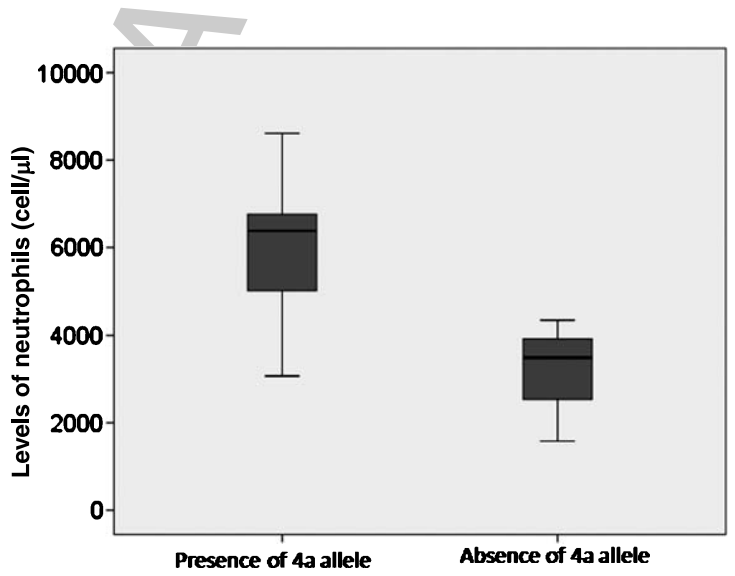

Fig. 3. Box plot of the distribution of levels of neutrophils in the presence or absence of eNOS4a allele at $e N O S$ gene. 
Table 4

Association between hematological and biochemical parameters and the haplotypes (T-G-4b (rs2070744- rs 1799983-intron 4 VNTR)/T-G-4b, T-G-4b/other e other/other) at eNOS gene

\begin{tabular}{|c|c|c|c|c|}
\hline Parameters & T-G-4b/T-G-4b & T-G-4b/Other & Other/Other & $p$-value \\
\hline Total $\mathrm{Hb}(\mathrm{g} / \mathrm{dL})$ & $8.90 \pm 1.49(4)$ & $8.60 \pm 1.38(15)$ & $8.42 \pm 0.98(4)$ & $0.880^{1}$ \\
\hline $\mathrm{Hb} \mathrm{S}(\%)$ & $74.15 \pm 3.87(4)$ & $75.31 \pm 7.10(14)$ & $73.67 \pm 8.26(4)$ & $0.897^{1}$ \\
\hline Total bilirubin (mg/dL) & $1.45 ; 1.26-1.65(2)$ & $1.94 ; 1.30-5.57(8)$ & $3.42 ; 1.39-5.46(2)$ & $0.322^{2}$ \\
\hline LDH (U/L) & $463.00 ; 410.00-516.00(2)$ & $451.00 ; 332.00-793.00(7)$ & $409.00 ; 328.00-490.00(2)$ & $0.769^{2}$ \\
\hline RDW (\%) & $21.00 \pm 1.55(2)$ & $22.01 \pm 2.60(7)$ & $23.80(1)$ & $0.670^{1}$ \\
\hline Reticulocyte count (\%) & $8.91 \pm 5.18(4)$ & $7.28 \pm 3.09(15)$ & $10.15 \pm 2.60(4)$ & $0.308^{1}$ \\
\hline $\begin{array}{l}\text { Levels of leukocytes } \\
\quad(\text { cell } / \mu \mathrm{L})\end{array}$ & $\begin{array}{c}8600.00 \\
7000.00-10200.00(2)\end{array}$ & $\begin{array}{c}10500.00 \\
9800.00-33100.00(7)\end{array}$ & $16800.00(1)$ & $0.149^{2}$ \\
\hline $\begin{array}{l}\text { Levels of neutrophils } \\
\quad(\text { cell } / \mu \mathrm{L})\end{array}$ & $2535.00 \pm 1350.57(2)$ & $5652.14 \pm 1880.28(7)$ & $6380.00(1)$ & $0.145^{1}$ \\
\hline ACP1 $(\mu \mathrm{mol} / \mathrm{g} \mathrm{Hb} / \mathrm{h})$ & $399.10 \pm 9.03(2)$ & $382.10 \pm 114.23(10)$ & $270.58 \pm 29.57(2)$ & $0.400^{1}$ \\
\hline MPO (ng/mL) & $26.11 \pm 0.39(2)$ & $41.11 \pm 19.41(9)$ & $34.01 \pm 23.00(3)$ & $0.588^{1}$ \\
\hline $\operatorname{MetHbR}(\mu \mathrm{mol} / \mathrm{g} \mathrm{Hb} / \mathrm{min})$ & $27.65(1)$ & $25.38 \pm 9.77(10)$ & $14.98 \pm 3.65(2)$ & $0.365^{1}$ \\
\hline TMR (mmol/lcell/h) & $4.71(1)$ & $5.31 \pm 1.23(3)$ & $(0)$ & $0.713^{1}$ \\
\hline
\end{tabular}

${ }^{1}$ ANOVA test - Mean \pm standard deviation ( - sample size). ${ }^{2}$ Kruskal-Wallis test - Median; minimum - maximum (n - sample size).

association of the a allele with higher number of neutrophils may be related with eNOS haplotypes, instead of $e N O S$ genotypes alone. In fact, that has been suggested in other studies [13, 22]. However we did not observe statistically significant differences once analyzing haplotypes, probably because of the low sample size.

Our results reinforce the importance of NO bioactivity in SCA. We presume that NO, and its precursors might be used as therapy to improve the quality of life of SCA patients.

\section{Acknowledgements}

We are grateful to patients and their families.

\section{References}

[1] R. Armstrong, The physiological role and pharmacological potential of nitric oxide in neutrophil activation, Int Immunopharmacol 1(8) (2001), 1501-1512.

[2] S.K. Ballas and P. Connes, The paradox of the serrated sickle erythrocyte: The importance of the red blood cell membrane topography, Clin Hemorheol Microcirc 63(2) (2015), 149-152. doi: 10.3233/CH-152014

[3] P.G. Board and M.E. Pidcock, Methaemoglobinaemia resulting from heterozygosity for two NADH-Methaemoglobin reductase variants: Characterization as NADH-Ferricyanide reductase, Br J Haematol 47 (1981), 361-370.

[4] M. Buraczynska, P. Ksiazek, W. Zaluska, T. Nowicka and A. Ksiazek, Endothelial nitric oxide synthase gene intron 4 polymorphism in patients with end-stage renal disease, Nephrol Dial Transplant 19(9) (2004), 2302-2306.

[5] J.P. Casas, L.E. Bautista, S.E. Humphries and A.D. Hingorani, Endothelial Nitric Oxide Synthase Genotype and Ischemic, Circulation 109 (2004), 1359-1365.

[6] J.P. Casas, G.L. Cavalleri, L.E. Bautista, L. Smeeth, S.E. Humphries and A.D. Hingorani, Endothelial nitric oxide synthase gene polymorphisms and cardiovascular disease: A HuGE review, Am J Epidemiol 164(10) (2006), 921-935.

[7] A. Coelho, A. Dias, A. Morais, B. Nunes, E. Ferreira and I. Picanço, et al., Genetic variation in CD36, HBA, NOS3 and VCAM1 is associated with chronic haemolysis level in sickle cell anaemia: A longitudinal study, Eur J Haematol 92(3) (2014), 237-243.

[8] J.W.W. Coleman, Nitric oxide in immunity and inflammation, Int Immunopharmacol 1(8) (2001), $1397-1406$. 
[9] J. Dissing, O. Dahl and K. Svensmark, Phosphonic and arsonic acids as inhibitors of human red cell and phosphatase and their use in affinity chromatography, Biochim Biophys Acta 569 (1979), 159-176.

[10] A. Driss, K.O. Asare, J.M. Hibbert, B.E. Gee, T.V. Adamkiewicz and J.K. Stiles, Sickle cell disease in the post genomic era: A monogenic disease with a polygenic phenotype, Genomics Insights 2(1) (2009), 23-48.

[11] R. Hillermann, K. Carelse and G.S. Gebhardt, The Glu298Asp variant of the endothelial nitric oxide synthase gene is associated with an increased risk for abruptio placentae in pre-eclampsia, J Hum Genet 50(8) (2005), 415-419.

[12] Y. Lamarre, M.D. Hardy-Dessources, M. Romana, M.L. Lalanne-Mistrih, X. Waltz and M. Petras, et al., Relationships between systemic vascular resistance, blood rheology and nitric oxide in children with sickle cell anemia or sickle cell-hemoglobin C disease, Clin Hemorheol Microcirc 58(2) (2014), 307-316.

[13] I.F. Metzger, D.C. Souza-Costa, A.S. Marroni, S. Nagassaki, Z. Desta and D. Flockhart, et al., Endothelial nitric oxide synthase gene haplotypes associated with circulating concentrations of nitric oxide products in healthy men, Pharmacogenet Genomics 15(8) (2005), 565-570.

[14] A. Mozar, P. Connes, B. Collins, M.D. Hardy-Dessources, M. Romana and N. Lemonne, et al., Red blood cell nitric oxide synthase modulates red blood cell deformability in sickle cell anemia, Clin Hemorheol Microcirc 2016. doi: $10.3233 / \mathrm{CH}-162042$

[15] E.P. Orringer and M.E. Roer, An ascorbate-mediated transmembrane- reducing system of the human erythrocyte. J Clin Invest 63 (1979), 53-58.

[16] A. Pulkkinen, L. Viitanen, A. Kareinen, S. Lehto, I. Vauhkonen and M. Laakso, Intron 4 polymorphism of the endothelial nitric oxide synthase gene is associated with elevated blood pressure in type 2 diabetic patients with coronary heart disease, J Mol Med 78(7) (2000), 372-379.

[17] K. Sharan, S. Surrey, S. Ballas, M. Borowski, M. Devoto and K.F. Wang, et al., Association of T-786C eNOS gene polymorphism with increased susceptibility to acute chest syndrome in females with sickle cell disease, Br J Haematol 124(2) (2004), 240-243.

[18] M.H. Steinberg and P. Sebastiani, Genetic modifiers of sickle cell disease, Am J Hematol 87(8) (2012), $795-803$.

[19] A.A.G. Tantawy, A.A.M. Adly, E.A.R. Ismail and S.H. Aly, Endothelial nitric oxide synthase gene intron 4 VNTR polymorphism in sickle cell disease: Relation to vasculopathy and disease severity, Pediatr Blood Cancer 62 (2015), 389-394.

[20] S.L. Thein and S. Menzel, Discovering the genetics underlying foetal haemoglobin production in adults, Br J Haematol 145(4) (2009), 455-467.

[21] A.E. Vargas, M.A.L. Da Silva, L. Silla and J.A.B. Chies, Polymorphisms of chemokine receptors and eNOS in Brazilian patients with sickle cell disease, Tissue Antigens 66 (2005), 683-690.

[22] J. Wang, D. Dudley and X.L. Wang, Haplotype-Specific Effects on Endothelial NO Synthase Promoter Efficiency Modifiable by Cigarette Smoking, Arterioscler Thromb Vasc Biol 22(5) (2002), 1-8.

[23] Y. Wang, S. Kikuchi, H. Suzuki, S. Nagase and A. Koyama, Endothelial nitric oxide synthase gene polymorphism in intron 4 affects the progression of renal failure in non-diabetic renal diseases, Nephrol Dial Transplant 14(12) (1999), 2898-2902.

[24] K.C. Wood, L.L. Hsu and M.T. Gladwin, Sickle cell disease vasculopathy: A state of nitric oxide resistance, Free Radic Biol Med 44(8) (2008), 1506-1528. 